\title{
The temperature field of a gravitationally cast ductile-cast-iron roller and its chemical and structural heterogeneity
}

\author{
F. Kavicka ${ }^{1}$, J. Dobrovska ${ }^{2}$, K. Stransky ${ }^{1}$, B. Sekanina ${ }^{1}$ \& J. Stetina ${ }^{1}$ \\ ${ }^{1}$ Brno University of Technology, Czech Republic \\ ${ }^{2}$ VSB-TU Ostrava, Czech Republic
}

\begin{abstract}
The quality of the working rollers from ductile-cast-iron used for rolling rails is determined by the chemical and structural composition of the material of the rollers and the production technology. The requirements of the quality cannot be ensured without perfect knowledge of the course of solidification, cooling and heat treatment of the cast rollers as well as the kinetics of the temperature field of the casting and mould. An original application of ANSYS simulated the forming of the temperature field of the entire system. In the experimental investigation of temperature field, an original methodology for the measurement of the distribution of temperatures and heat flows in the roller-mould system had been developed and verified in the operation. The kinetics of the solidification has a measurable and non-negligible influence on the chemical and structural heterogeneity of the investigated type of ductile-cast-iron. Tying on to the results of the model of the temperature field of the cast rollers, an original methodology was developed for the measurement of chemical microheterogeneity. The structure of this cast-iron is created by a great amount of the transition form of graphite and small amount of globular graphite and also lamellar graphite and cementite, whereas the structure of the metal matrix is perlitic. The chemical and structural heterogeneity of the cast roller is therefore a significant function of the method of melting, modification and inoculation and the successive procedures of risering, casting and crystallization after cooling.

Keywords: cast-iron rollers, solidification and cooling, temperature field, numerical model, chemical and structural heterogeneity, measurement.
\end{abstract}




\section{Introduction}

Steel and ductile cast-iron rollers, between which train rails (with a hardness of $300 \mathrm{HB}$ ) are rolled, are cast into cylindrical iron moulds. Each producer uses their own production technology that must meet the increasingly more demanding requirements concerning length of operational life on the railway i.e. greater hardness. This means that it is necessary to cast rollers with significantly improved utility properties, mainly high wear-resistance and optimal mechanical and structural properties. It is therefore necessary to find and ensure optimal relationships between the matrix structure and the resultant values of the mechanical properties of the rollers in order to maximize the length of life. The requirements introduced here cannot be met without perfect knowledge of the course of solidification, cooling and heat treatment of the cast rollers as well as the kinetics of the temperature field of the casting and mould [1].

The solidification and cooling of these rollers - partly inside a sand mould and partly inside an iron mould - is a very complicated problem of heat and mass transfer with a phase and structural change. The investigation into the temperature field, which can be described by the 3D Fourier equation, is not possible without the engagement of a numerical model of the temperature field of the entire system - comprising the casting, the mould and ambient [2, 3]. An original application of ANSYS simulated the forming of the temperature field of the entire system. The introduced 3D model of the temperature field is based on the numerical finite-element method. Experimental research and temperature measurement must be conducted simultaneously with numerical calculation in order to make the model more accurate and to verify it [2, 3].

The kinetics of the solidification has a non-negligible influence on the chemical and structural heterogeneity of the cast-iron in question [3]. An original methodology for the measurement of microheterogeneity had been developed based on the results of the model of the temperature field of the cast rollers. The chemical and structural heterogeneity of the cast roller has proven to be a significant function of the method of melting, modification and inoculation and the successive procedures of risering, casting and crystallization after cooling.

\section{The assignment and preparation of the investigation}

The assignment focused on investigating the transient 3D temperature field of a system comprising a casting, the mould and ambient, using a numerical model. The dimensions of the cylindrical casting and of the iron mould are given in Fig. 1; the diameter of the actual roller is $1180 \mathrm{~mm}$ and height $2100 \mathrm{~mm}$. This figure illustrates the entire set-up comprising two parts of the sand mould for the upper and lower spindle ends and the iron mould. The working surface of the iron mould is covered with a separating layer - hereafter "separator" (which is a special lubricant applied in various thicknesses to the inside walls of the iron mould and kiln-hardened at $180^{\circ} \mathrm{C}$ prior to casting). The initial temperature of the mould was $20^{\circ} \mathrm{C}$. The pouring temperature of the melt was $1336^{\circ} \mathrm{C}$. 


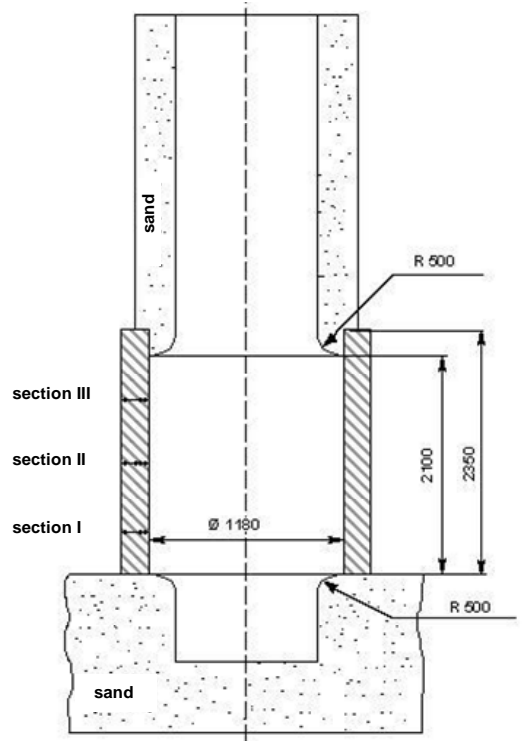

Figure 1: $\quad$ The set-up of a vertically cast roller.

The casting was performed from underneath with tangential in-flow. The total time of casting of the ductile cast-iron was 175 seconds. The chemical composition is given in Table 1.

Table 1: $\quad$ The chemical composition of ductile cast-iron B10.

\begin{tabular}{|c|c|c|c|c|c|c|c|c|c|c|}
\hline \multicolumn{10}{|c|}{ Cast-iron B10 } \\
\hline Element & $\mathrm{C}$ & $\mathrm{Mn}$ & $\mathrm{Si}$ & $\mathrm{P}$ & $\mathrm{S}$ & $\mathrm{Cr}$ & $\mathrm{Ni}$ & $\mathrm{Mo}$ & $\mathrm{Mg}$ & $\mathrm{Cu}$ \\
\hline Content & 3.31 & 0.65 & 0.7 & 0.105 & 0.00 & 0.35 & 2.5 & 0.59 & 0.04 & 1.48 \\
\hline
\end{tabular}

Since this is a case of rotational symmetry, it was sufficient to investigate the temperature field of one half of the axial section. The coefficients of heat transfer by radiation and convection in all planes bordering the system into the ambient were defined. Ideal physical contact was presumed between the sand mould and the casting.

\subsection{Numerical model of the temperature field of the roller}

The mathematical model for the simulation of the temperature field of the rollermould system was created by ANSYS. The element Plane 55 was selected for the calculation. It has 4 nodes with one unknown - the temperature. The simulation of the release of the latent heats of phase or structural changes is carried out by introducing the thermodynamic enthalpy function [3]. The model enables the evaluation of the temperature field within the actual casting and mould at any point in time within the process of solidification and cooling using 
contour lines (i.e. so-called iso-lines and iso-zones) or temperature-time curves for any nodal point of the system. It is possible to use all sophisticated subprograms of ANSYS, such as automatic mesh generation, pre-processing and post-processing. The program also considers the non-linearity of the task, i.e.:

- The dependence of the thermophysical properties of all materials entering the system, and

- The dependence of the heat-transfer coefficients (on all boundaries of the system) on the temperature of the surface - of the casting and mould.

A series of experimental temperature measurements was conducted for the verification of the model and the closer determining of the boundary conditions of the numerical solution of the temperature field. Results from experimental measurements were used for verification of the model and correction of the boundary conditions of the numerical solution of the temperature field. The calculation of the temperature field dealt mainly with the effect of the separator between the casting and the iron mould on the solidification of the roller.

\subsection{The results of the simulation of the temperature field in dependence on the separator thickness [1]}

The thickness of the separator - for individual simulations of solidification and cooling of the roller - was gradually $0,5,10$ and $15 \mathrm{~mm}$. The point where the melt solidifies last is the centre $-2100 \mathrm{~mm}$ from the base of the iron mould. The centre of the body of the roller is on the axis at a distance of $1050 \mathrm{~mm}$ from the same base. Table 2 contains the solidification times of the entire roller (including its centre), which are calculated from the simulation.

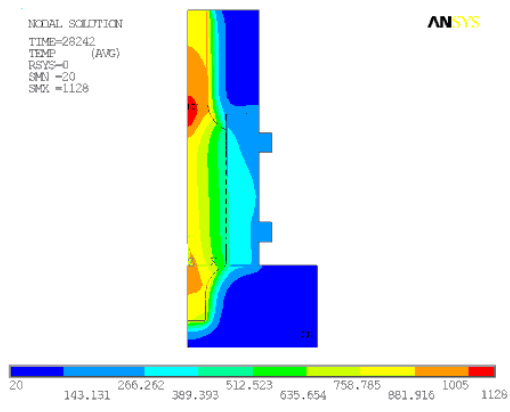

a)

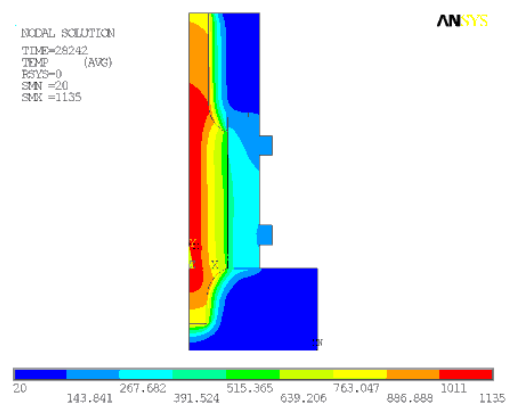

b)

Figure 2: The temperature field along the longitudinal section a) without the separator, b) with a $15 \mathrm{~mm}$ separator.

Figure 2 illustrates the temperature field along the longitudinal axis of the system for two thicknesses ( 0 and $15 \mathrm{~mm}$ ) after $7.845 \mathrm{~h}$, i.e. at the time when the centre of the roller solidifies with a separator of a mean thickness of $10 \mathrm{~mm}$ (Table 2). 
Table 2: $\quad$ Solidification times for various separator thicknesses.

\begin{tabular}{|c|c|c|c|c|}
\hline \multirow{3}{*}{$\begin{array}{c}\text { Separator } \\
\text { thickness }\end{array}$} & \multicolumn{4}{|c|}{ Solidification time } \\
\hline & \multicolumn{2}{|c|}{ Centre of roller } & \multicolumn{2}{|c|}{ Entire roller } \\
\hline & hours & seconds & hours & seconds \\
\hline 15 & 8.187 & 29473 & 8.783 & 31618 \\
\hline 10 & 7.845 & 28242 & 8.124 & 29246 \\
\hline 5 & 7.030 & 25310 & 7.531 & 27111 \\
\hline 0 & 6.510 & 23437 & 6.554 & 23593 \\
\hline
\end{tabular}

It is possible to observe an enlargement of the area where the maximum temperature occurs (red area) along the vertical axis with an increasing thickness of separator. Fig. 3 shows the dependence of the total solidification time of the centre of the roller and entire roller on the separator thickness. The relationship between the separator thickness and the solidification time can be described in relatively great detail by the linear function - as the reliability coefficient values in Fig. 3 indicate for both straight lines. The separator has proven to be a good insulator. The solidification time of the roller inside the mould with a $15 \mathrm{~mm}$ separator increases by up to $26 \%$ compared to that without the separator.

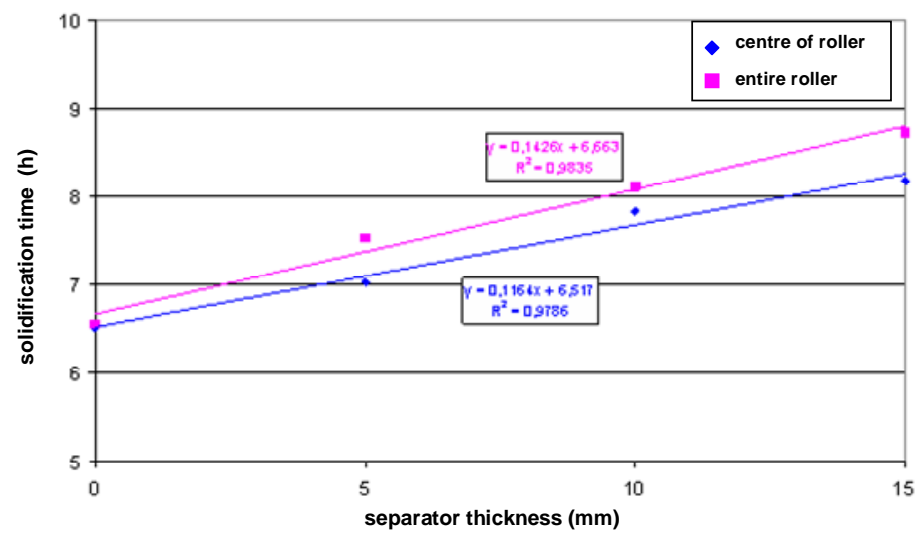

Figure 3: The influence of the separator thickness on the total solidification time.

\subsection{Experimental measurement of the temperatures inside the iron mould and on the surface of the roller}

The distribution of temperatures along the height of the iron mould and roller was measured in three horizontal planes, $100 \mathrm{~mm}$ (section I), $1000 \mathrm{~mm}$ (section II) and $1950 \mathrm{~mm}$ (section III) from the bottom edge of the iron mould (Fig. 1). The temperatures of the iron mould were taken beneath the inner surface 
(at depths of 5 and $10 \mathrm{~mm}$ ) and outer surface (at a depth of $5 \mathrm{~mm}$ ). The sensors for measuring the temperature of the roller took the temperatures at a depth of $5 \mathrm{~mm}$ beneath the surface in the same horizontal planes as the temperatures of the iron mould. The temperature was measured in a total number of 14 points where 3 were on the surface of the roller, 7 on the inner surface of the iron mould and 4 points on the outer surface of the iron mould. The thermocouples were interconnected using the compensation leads of the 12-bit GRANT 1250 and 1203 measurement stations with 87 and $46 \mathrm{~KB}$ of memory respectively.

\subsection{Calculated versus measured temperatures}

Section III, where thermocouples recorded the temperatures the longest specifically point 9 (the inner surface of the iron mould) - had been selected for the comparison of the temperatures from the numerical simulation with the experimentally obtained temperatures from inside the iron mould.. The results of this comparison are illustrated in Fig. 4. It confirms a very close similarity of the calculated and measured temperatures of the iron mould. The maximum values of the linear density of the heat flow were found to be in section II. On average, they are $100 \mathrm{~kW} . \mathrm{m}-1$ higher than those of section III and section I. The intensity of the heat transfer influenced the formation of the pouring structure monitored on the samples taken from sections I and III (see part 3 of this article).

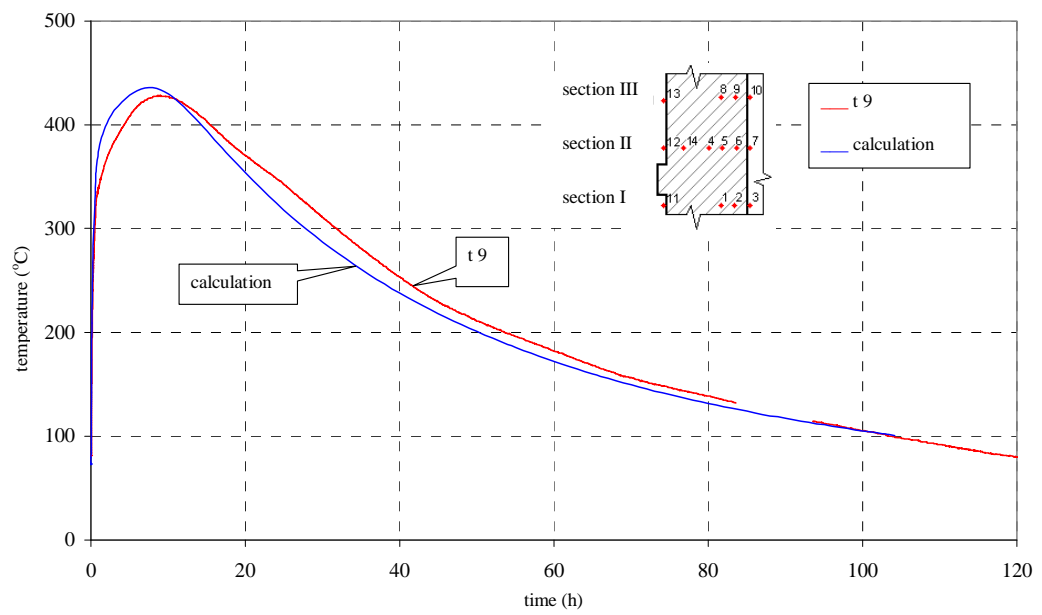

Figure 4: $\quad$ Calculated versus measured temperatures (point 9).

The results of the mathematical model indicate that the distribution of temperatures and the course of solidification in the vertical direction is quite uneven, which affects the internal quality of the casting. While the body of the roller is solidified along the entire height, the temperatures are still high in the lower spindle and could be the cause of shrinkage porosity in the point where the spindle enters the roller. That is why the lower spindle should solidify in a mould 
with a higher heat accumulation, i.e. in a mould made of CT-CrMg or in an iron mould. Sooner topping-up of the upper spindle should ensure replenishing of the mould with melt into the body of the roller in order to achieve increased quality.

\section{Structural and chemical heterogeneity of the roller}

The final mechanical properties of the rollers - of ductile cast-iron - are determined, not only by the chemical composition but mainly by their structural and chemical heterogeneity, which occurs during casting, crystallization and successive cooling of the material. Some defects occurring in this way can be corrected by heat treatment however the quality of the pouring structure is very important especially with graphite cast-iron.

The samples used for determining the structural and chemical heterogeneity were taken from the ductile cast-iron roller (Fig. 1) with the chemical composition given in Table 1 from the upper part (section III) and from the bottom part (section I). Figure 5 shows how the four samples were taken, with the upper surfaces - marked " $X$ " - being analyzed. Further, they were specified as follows:

- The upper part of the roller on the outer surface (R1=540 mm) marked TR1,TR2

- The upper part of the roller on the inner surface (R4=400 mm) marked TR3,TR4

- The lower part of the roller on the outer surface marked BR1,BR2

- The lower part of the roller on the inner surface marked BR3,BR4

The actual analyses were conducted at a specialized workplace $[4,5]$

The connection of the measured area of the ductile cast-iron to its microstructure can be seen in Fig. 6, obtained using the light microscope.

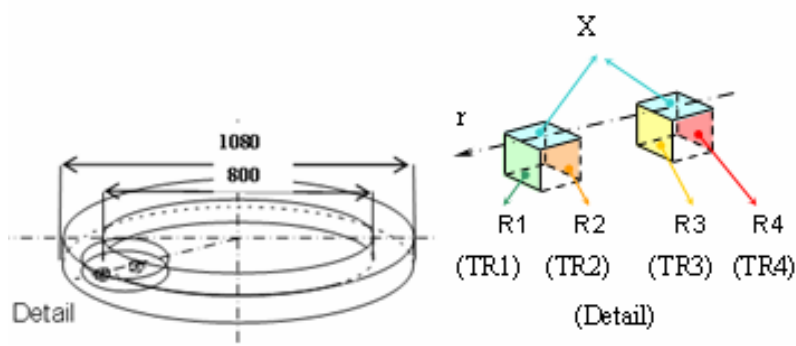

Figure 5: $\quad$ Sampling.

The structural analysis of the cast-iron samples was conducted using the Neophot 32 metallographic microscope and an Olympus digital camera. The measurements of the metallographic parameters of the graphite and the evaluation of the volume part of the structural components were conducted on the Olympus CUE4 image analyzer. The basic statistical parameters of the graphite particles and also the stereological estimate of certain other parameters [4] were calculated from the data files. The JSM-840 (JEOL) electron 

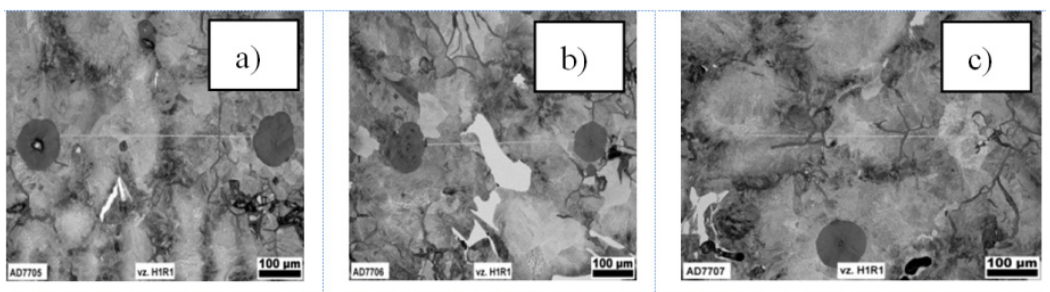

Figure 6: The structures in the area of sample TR1 selected for analysis: a) between the spherical graphite through perlite, b) between the spherical graphite through cementite, c) through lamellar graphite.

scanning microscope was used for determining the chemical heterogeneity together with the LINK AN 10/85S X-ray energy-dispersive microanalyzer. Based on the results of the metallographic analysis [4], two pairs of graphite grains were selected on the ground surface of every sample in order for the line of measurement between the first pair to pass through the perlite (marked "a") and the cementite (marked "b"). The third line was selected through two boundaries created by particles of lamellar graphite, where measurement passes through basic perlite (marked “c”). The individual elements ( $\mathrm{Si}, \mathrm{P}, \mathrm{Mo}, \mathrm{Cr}, \mathrm{Mn}$, $\mathrm{Fe}, \mathrm{Ni}$, and $\mathrm{Cu}$ ) were analyzed by means of point $\mathrm{X}$-ray microanalysis in a direct line with a step of $3 \mu \mathrm{m}$ [5]. Following the chemical (element) analysis, the samples were etched using $2 \%$ nital in order to make the contamination traces visible and display the line of measured points, incl. their connection to the sample microstructure.

\subsection{Structural heterogeneity}

Based on experience, it can be assumed that the structure of the material of the casting (named “ductile cast-iron” for working purposes) will, besides globular graphite that is characteristic for ductile cast-iron, also contain a mixture of a certain amount of transition forms of graphite and lamellar graphite found between the globular and lamellar graphite. Table 3 shows the results from the quantitative metallographic analyses of the structures of the samples in Fig. 5. The procedure of the quantitative structural measurements, including the results, is described in detail in a special report [4]. Table 3 indicates that the least amount of graphite in the structure can be found in the bottom part of the roller and along the outer edge of the ring - in sample BR1 (Fig. 5). A greater amount of graphite is segregated near the inner edge of the ring - in sample BR4 - the wall R3. Along the height of the roller, the amount of graphite increases - in samples TR1 and TR4. On the wall R3 it is greatest however simultaneously the standard deviation of the measurement and the amount of micro-shrinkages also increases. Globular graphite, which makes up the typical structure of the ductile cast-iron, represents the minority phase of this material and its amount is merely 1.3 of the volume percentage, it is highest in the bottom part of the roller along the outer edge of the ring, where the casting cools the quickest, i.e. in sample 
BR1. The lowest amount of transfer forms of graphite, including lamellar graphite are segregated in this area. Cementite, which is the component of greatest hardness is segregated approximately twice as much as at the outer walls of the ring, which cool faster than the inner walls. The perlite structure of the roller dominates and its volume content is $85.9 \pm 1.19 \%$. The relatively greater amount of perlite is in the lower part of the roller however the volume percentage difference of 1.3 is insignificant.

Table 3: The results from the quantitative measurements of the volume part of the components (in vol. \%).

\begin{tabular}{|l|l|l|l|l|l|}
\hline Sample & $\begin{array}{l}\text { All graphite, } \\
\text { incl. micro-shrinkages }\end{array}$ & $\begin{array}{l}\text { Globular } \\
\text { graphite }\end{array}$ & $\begin{array}{l}\text { Transition forms of graphite } \\
\text { and lamellar graphite }\end{array}$ & Cementite & Perlite \\
\hline BR1 & $10.5 \pm 2.8$ & 1.3 & 9.2 & $2.2 \pm 1.7$ & 87.3 \\
\hline BR3 & $13.0 \pm 5.4$ & 1.1 & 11.9 & $1.2 \pm 1.2$ & 85.8 \\
\hline TR1 & $13.4 \pm 5.6$ & 1.1 & 12.3 & $2.2 \pm 1.8$ & 84.4 \\
\hline TR3 & $12.6 \pm 5.7$ & 1.1 & 11.5 & $1.3 \pm 1.4$ & 86.1 \\
\hline
\end{tabular}

\subsection{Chemical heterogeneity}

The distribution of the concentration of the eight elements, measured three times in one line for each of the samples (Fig. 6: a, b, c) was evaluated using mathematical statistics: the arithmetic mean of the concentration of the element in the selected interval $\mathrm{c}_{\mathrm{st}}$, the standard deviation $\sigma_{\mathrm{n}-1}$ of the measured concentration, the minimum concentration $\mathrm{c}_{\min }$ and the maximum $\mathrm{c}_{\max }-$ measured each time in the selected interval of the sample (in wt. \%). Besides these basic concentration parameters, the segregation index of each measured element was determined and defined as $\mathrm{I}_{\mathrm{S}}=\mathrm{c}_{\max } / \mathrm{c}_{\mathrm{st}}$, i.e. as the quotient of the maximum concentration of elements measured on the given interval and the arithmetic mean of its concentration in the same interval. The tendency of the element to segregate - based on experience - is expressed in the values of the segregation indexes. A detailed description of the measurement procedure and the corresponding results can be found in reports [5]. Figure 7a illustrates the values of this parameter for individual elements and samples measured in one line across the lamellar graphite - c. Similarly, the segregation index values can be plotted for the area between the globular graphite in a line across perlite - a, and also in the area between the globular graphite in a line across cementite - b. Figure $7 \mathrm{~b}$ shows the segregation index values for the elements calculated as the average of the values for all three areas - a, b, c.

The graphs in Fig. 7 also indicate that the segregation indexes of the highest values - from the set of measured elements - belong to phosphorus and molybdenum, and the lowest values refer to nickel and iron which make up the matrix. In the segregation of elements during crystallization, solidification and cooling of the roller the sequence of the indexes of element segregation for all three types of measured lines through the different structures (Fig. 6 a-c) remains unchanged - in the order $\mathrm{P}, \mathrm{Mo}, \mathrm{Cr}, \mathrm{Mn}, \mathrm{Cu}, \mathrm{Si}, \mathrm{Ni}, \mathrm{Fe}$, i.e. from the 

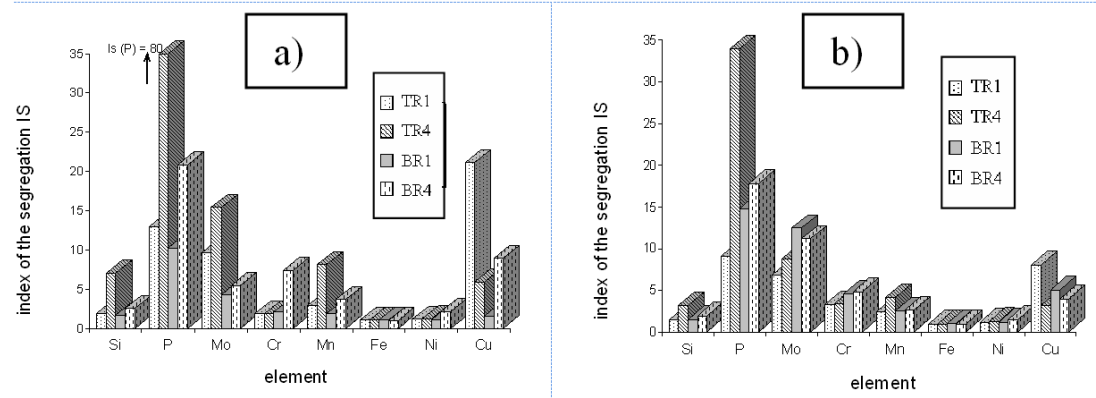

Figure 7: a) The index of the segregation of elements for individual samples in the area of the transition graphite in the measured area across lamellar graphite, b) The average index of segregation of the analyzed elements in individual samples

element with the highest segregation index to the element with the lowest. This same sequence applies to the top and bottom parts of the roller. Phosphorus and molybdenum therefore always have the greatest tendency towards segregation and nickel always has the least (if the iron which makes up the matrix is neglected). The elements in the middle of the sequence ( $\mathrm{Cr}, \mathrm{Mn}, \mathrm{Cu}, \mathrm{Si}$ ) can mutually alter the order in which they come depending on certain measured lines - there were as many as 12 lines).

According to the theory of segregation of elements in a melt of pure iron the partition coefficient of the element between the solid and liquid phase determines the intensity of segregation. Table 4 introduces the partition coefficients of elements in the order from the smallest to the biggest value [6].

It is remarkable (Table 4) that in the real melt of a roller it is only the elements on the ends of the sequences, i.e. phosphorus (which segregates the most) and iron (which makes up the basic component of the solution and whose partition coefficient is equal to one). The remaining elements have a completely different position in the sequence according to the previous table. This shows that the crystallization, solidification and cooling of the roller which has a 3.31 wt. \% C content, whose chemical composition is given in Table 1, will, as a result of the crystallization of graphite, significantly deviate from the method of crystallization, solidification and cooling of the melt of steel in binary systems or alloys with low carbon content.

Table 4: The partition coefficients of elements.

\begin{tabular}{|l|l|l|l|l|l|l|l|l|}
\hline Element $\mathrm{i}$ at $1600^{\circ} \mathrm{C}[9]$ & $\mathrm{P}$ & $\mathrm{Si}$ & $\mathrm{Mn}$ & $\mathrm{Ni}$ & $\mathrm{Mo}$ & $\mathrm{Cu}$ & $\mathrm{Cr}$ & $\mathrm{Fe}$ \\
\hline $\begin{array}{l}\text { Partition coefficient } \mathrm{k}_{\mathrm{i}} \text { in binary } \\
\text { solution (Fe-i) }\end{array}$ & 0,13 & 0,64 & 0,68 & 0,69 & 0,72 & 0,80 & 0,90 & $\sim 1$ \\
\hline $\begin{array}{l}\text { Element } \mathrm{i} \text { - according to actual } \\
\text { measurement }\end{array}$ & $\mathrm{P}$ & $\mathrm{Mo}$ & $\mathrm{Cr}$ & $\mathrm{Mn}$ & $\mathrm{Cu}$ & $\mathrm{Si}$ & $\mathrm{Ni}$ & $\mathrm{Fe}$ \\
\hline $\begin{array}{l}\text { Partition coefficient } \mathrm{k}_{\mathrm{P}} * \approx \mathrm{I}_{\mathrm{S}}{ }^{-1} \\
{[7,8] \text { in real solution (roller), }} \\
\text { measured on surface R1 (Fig. 5) }\end{array}$ & 0,11 & 0,19 & 0,46 & 0,62 & 0,80 & 0,69 & 0,88 & 0,99 \\
\hline
\end{tabular}




\section{Conclusion}

The calculation of the temperature field focused on the analysis of the effect of the mould separator on the course of solidification of the roller. The results of the mathematical modelling indicate that the distribution of temperatures and the solidification in the vertical direction is significantly uneven - this has an effect on the internal quality of the casting. While the body of the roller is solidified along the entire length, the bottom spindle still has areas with high temperatures and this is the cause of contractions and hollows in the area where the spindle enters the roller. It is therefore advisable for the bottom spindle to solidify in a mould made of a mixture of a higher coefficient of heat accumulation.

The numerical model of temperature field does not include the numerical model of heterogeneity. Phase or structural changes are expressed by numerical simulation of the release of their latent heats. The known function enthalpytemperature contains the latent heat of each change. The temperature field of the casting-mould-ambient system is simulated from the moment, when the pouring is finished. This simplifying assumption is also confirmed by experiments (regarding short pouring time $175 \mathrm{~s}$ ).

This article introduces an original methodology for the measurement of the chemical heterogeneity of ductile cast-iron. The structure of this cast-iron is created by a great amount of the transition form of graphite and small amount of globular graphite and also lamellar graphite and cementite, whereas the structure of the metal matrix is perlitic. The volume amounts of the structural components were determined using the quantitative metallographic analysis, which was simultaneously the basis for the selection of the places for the analysis of the element composition using X-ray energy-dispersive spectral microanalysis. Inside the microstructure of four samples, taken from the outer and inner parts of the ring at the top and bottom of the roller (Fig. 2), in a total of twelve areas, the linear concentration dispersion was measured on the eight elements which make up the basic constitution of the cast-iron: $\mathrm{Si}, \mathrm{P}, \mathrm{Mo}, \mathrm{Cr}, \mathrm{Mn}, \mathrm{Fe}, \mathrm{Ni}$, and $\mathrm{Cu}$. Statistical analysis was used to determine the distribution characteristics of the concentration of the individual elements, including the segregation indexes and the relationships among them. In this way it was possible to assess the influence of the changing kinetics of the temperature field on the resultant structural and chemical heterogeneity of the roller. The greatest speed of crystallization, solidification and cooling relates to those samples which had been taken from the bottom part of the roller and the outer edge of the ring, and the samples from the top part of the roller on the inner side of the ring cooled the slowest. Simultaneously, during the successive processes of crystallization, solidification and cooling, the constant reducing sequence of the element segregation indexes in the order: $\mathrm{P}, \mathrm{Mo}, \mathrm{Cr}, \mathrm{Mn}, \mathrm{Cu}, \mathrm{Si}, \mathrm{Ni}, \mathrm{Fe}$, which corresponds to the greatest heterogeneity in the distribution of $\mathrm{P}$ and $\mathrm{Mo}$ in the distribution of $\mathrm{Ni}$ and $\mathrm{Fe}$. Comparing with the generally known kinetics of the segregation of the same elements in low-carbon steels, it is clear that the conditions connected with the forming of graphite, through which the crystallization, solidification and cooling of the cast-iron of the measured high-carbon-content roller pass, are significantly 
different from the conditions of solidification of gravitationally cast low-carbonsteel castings. The kinetics of the solidification of the cast-iron roller had a nonnegligible influence on the chemical and structural heterogeneity of the investigated type of cast-iron.

Section 3 describes the experimental research of the structural and chemical heterogeneity and the quality of the pouring structure of the roller. It is obvious that the chemical and structural heterogeneity of the cast roller is a significant function of the method of melting, modification and inoculation and the successive procedures of risering, casting and crystallization after cooling.

\section{Acknowledgement}

This analysis was conducted using a program devised within the framework of the GA CR project No. 107/11/1566.

\section{References}

[1] Molinek, J., et al. Optimization of technological parameters of the gravitycast rolls for rolling rails. Final research report of the project GACR 106/04/1334, Ostrava, Czech Republic, 2007.

[2] Kavicka F., et al. A numerical model of the crystallization of pure aluminium. Fluid Structure Interaction and Moving Boundary Problems, WIT press Southampton, Great Britain, pp. 619-629, 2005.

[3] Kavicka F., et al. Numerical optimization of the method of cooling of a massive casting of ductile cast-iron. Book of Abstracts and CD ROM of the 13th International Heat Transfer Conference, Sydney, Australia, August, p. 27, 2006.

[4] Belko J., Stransky K. Structural analysis of cast-iron samples (in Czech). Research report, VTÚO Brno, Czech Republic, 2005.

[5] Winkler, Z., Stransky, K., Microheterogeneity of the composition ductile cast-iron samples alloyed with $\mathrm{Mn}, \mathrm{Cu}, \mathrm{Ni}$ and $\mathrm{Mo}$ (in Czech). Research report, VTÚO Brno, Czech Republic, 2005.

[6] Kuchar, L., Drapala, J. Metallurgy of pure metals (in Czech). Nadacia R. Kammela. Kosice, Slovak Republic, 2000. 